\title{
Effect of Agricultural Waste Material on the Properties of Portland Cement Pastes
}

ISSN: 2576-8840

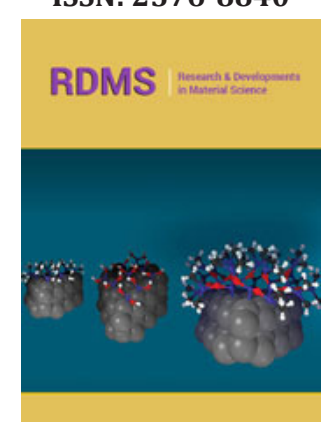

*Corresponding author: Darweesh HHM, Refractories, Ceramics and Building Materials Department, Egypt

\section{Submission: 趼 March 09, 2020

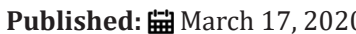

Volume 13 - Issue 1

How to cite this article: Darweesh HHM Abo El Suoud MR. Effect of Agricultural Waste Material on the Properties of Portland Cement Pastes. Res Dev Material Sci. 13(1).RDMS.000802.2020.

DOI: 10.31031/RDMS.2020.13.000802

Copyright@ Darweesh HHM, This article is distributed under the terms of the Creative Commons Attribution 4.0 International License, which permits unrestricted use and redistribution provided that the original author and source are credited.

\author{
Darweesh HHM ${ }^{1 *}$ and Abo El Suoud MR ${ }^{2}$ \\ ${ }^{1}$ Refractories, Ceramics and Building Materials Department, Egypt \\ ${ }^{2}$ Bottany Department, Egypt
}

\begin{abstract}
The effect of wheat stalk ash (WSA) on the physical, chemical and mechanical properties as well as the hydration of the cement pastes containing it was evaluated, and so it can provide a necessary theoretical basis and a practical guiding significance for practical engineering. It is concluded that WSA could be partially added to cement without any adverse effect on its specific properties, particularly the compressive strength. The free lime content, $\mathrm{Ca}(\mathrm{OH})_{2}$ is obviously decreased with WSA. The optimum WSA content was $20 \mathrm{wt}$. \%, and more than this amount, the specific properties of cement were declined. The polyprobyene admixture (PPP) is the mean reason responsible for the modification and improving most of physical, chemical, and mechanical properties of the hardened cement pastes. The pozzolanic reactions of WSA with $\mathrm{Ca}(\mathrm{OH})_{2}$ played a vital role to form additional CSH gel-phases that support and enhance the specific properties of the cement.
\end{abstract}

Keywords: Wheat straw ash; Cement; Setting; Density; Porosity; Strength

Abbreviations: C: $\mathrm{CaO}, \mathrm{S}: \mathrm{SiO}_{2}, \mathrm{~A}: \mathrm{Al}_{2} \mathrm{O}_{3}, \mathrm{~F}: \mathrm{Fe}_{2} \mathrm{O}_{3}, \mathrm{H}: \mathrm{H}_{2} \mathrm{O}, \mathrm{CH}: \mathrm{Ca}(\mathrm{OH})_{2}$, Calcium Silicate Hydrate (CSH), Silica Nano Particles (SNP)

\section{Introduction}

In agricultural countries as Egypt, Tunisia, China and India, gaseous emissions and air pollutants from open burning of agro waste residues are one of the most important sources of air pollution [1]. The biomass power plants are widely used for the disposal of biomass wastes so as to solve the environmental problems [2]. According, the wheat stalk ash, which is containing high amounts of active $\mathrm{SiO}_{2}$ and $\mathrm{Al}_{2} \mathrm{O}_{3}$, possesses a good pozzolanic reactivity with $\mathrm{Ca}(\mathrm{OH})_{2}$ evolved from the hydration of $\mathrm{C}_{3} \mathrm{~S}$ and $\beta-\mathrm{C}_{2} \mathrm{~S}$ phases of the cement so that it can be potentially reused as a supplementary cementitious material to be partially replaced with cement $[3,4]$.

The necessity to utilize waste materials either solids, liquids or even gases to decrease the overall energy consumption is becoming increasingly obvious worldwide. The benefits from applying pozzolanic materials as fly ash [5-7], granulated blast furnace slag [8-11], silica fume [9-12], rice husk ash [13,14], sugarcane bagasse ash [15,16], palm ash [17], saw dust ash $[18,19]$, and many others as a partial replacement of Portland cement in cement pastes, mortars and/or concretes are now well established [20-25]. These pozzolanic materials can improve their workability, strength and durability. It is well known that corn and wheat plants are the main food crop in tropical and subtropical countries because it plays a vital role in the countrywide economy of countries [26-31].

Wheat straw (WS) is a solid waste material generally disposed to the landfills or disposal sites so that it now represents a heavy environmental burden [30-32]. To reduce the environmental burden of the WS, its utilization in cement pastes, mortars or even concrete is a significant aspect. The burning of organic wastes, like WS, produces a considerable amount of ash. One of the effective ways to reduce the environmental impact is to reuse it as a mineral admixture for the partial substitution of cement, mortar and/or concrete, which can reduce its production cost, energy conservation, and waste emission [13,19,21,23,25,26,29]. Wheat straw ash (WSA) is acquired through the control burning of it. WSA could be used as a partial substitution material in cement pastes, mortars and/or concretes because it contains active and amorphous silica, which has pozzolanic characteristics [14-18,24,28]. 


\section{Objective of the current study}

In the current study, authors tried to exploit and utilize a larger amount of wheat straw ash (WSA) as a pozzolanic material in Portland cement pastes. The water of consistency and setting times, chemically bound water and free lime contents, bulk density, total porosity and compressive strength were investigated.

\section{Materials and Methods}

\section{Raw materials}

The raw materials used in the current research article are Ordinary Portland cement (OPC Type I- CEM I 42,5R) with the blaine surface area of $3400 \mathrm{~cm}^{2} / \mathrm{g}$, and wheat straw (WS) as a source of active nano silica with a fineness of $350 \mu \mathrm{m}$. The OPC was supplied from Sakkara cement factory, Giza, Egypt, of a commercial name as "Asmant El-Momtaz", while WS sample was taken from the Agricultural Research Centre (ARC), Giza, Egypt. The WS was first processed and washed with running water, and also with distilled water, and then let too dry under sun and open air for three days. The dried WS was subjected to firing in a muffle furnace up to 650 ${ }^{\circ} \mathrm{C}$ for three hours soaking time to produce what is known as wheat straw ash (WSA). The resulting WSA was manually ground and screened to pass through $300 \mu \mathrm{m}$ standard sieve. Polypropylene polymer (PPP) was added to the cement batch during mixing and casting, The PPP sample (Figure 1) was provided by Belgium Fibers Manufacturing Industrial Poulevard 91, B-7700 Mouscron, Belgium. The PPP sample was first processed to become suitable for using as an admixture for cement. The chemical analysis of both OPC and WSA samples which was measured by X-ray flourescense (XRF) is shown in Table 1. The SEM microscopy of WSA sample is shown in Figure 2. It could be seen that WSA exhibited various shapes and sizes as flocculent, flaky and fibroids. Particles of WSA are amorphous and crystalline, and it is mainly composed of a large percentage of nano-SiO ${ }_{2}$ and a lower percentage of nano- $\mathrm{Al}_{2} \mathrm{O}_{3}$. The mineralogical phase composition of the used OPC as calculated from Bogue equations [30,31] is given in Table 2, while the mix composition is illustrated in Table 3.

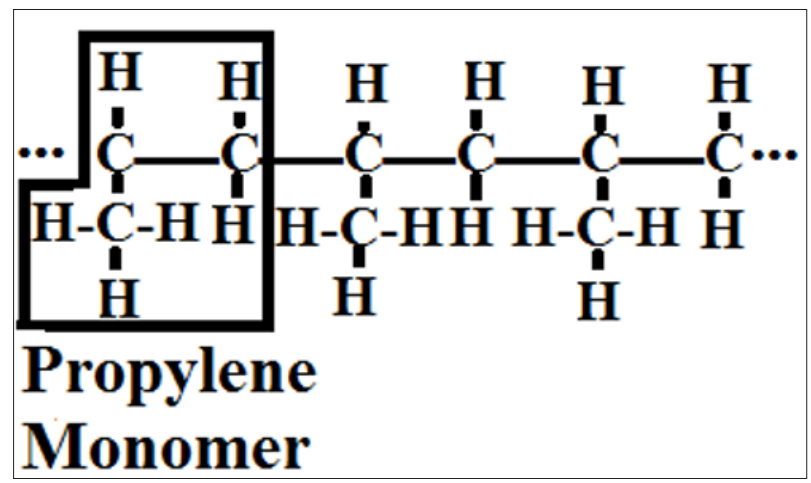

Figure 1: Chemical structure of Polypropylene polymer (PPP).

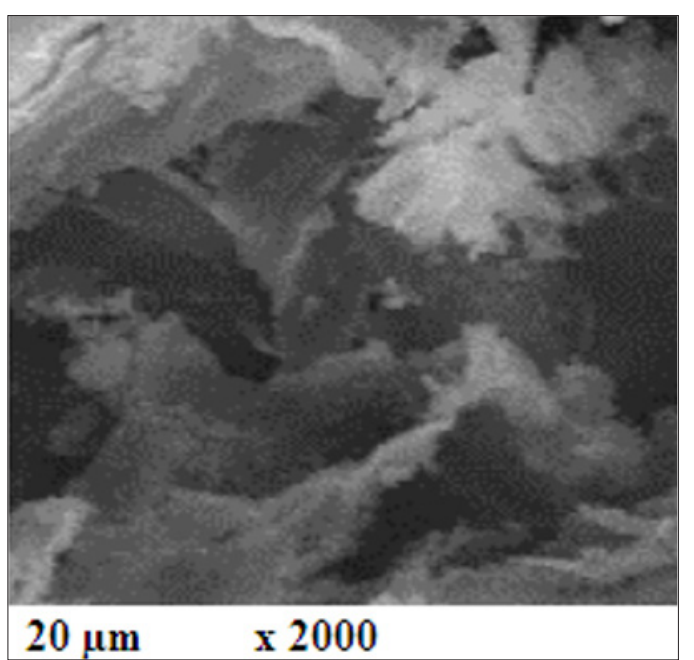

Figure 2: The SEM microscopy of the WSA.

Table 1: The chemical analysis of OPC and WSA specimens, mass \%.

\begin{tabular}{|c|c|c|c|c|c|c|c|c|c|c|c|c|}
\hline Oxid Material & $\mathbf{S i O}_{\mathbf{2}}$ & $\mathbf{A l}_{\mathbf{2}} \mathbf{O}_{\mathbf{3}}$ & $\mathbf{F e}_{\mathbf{2}} \mathbf{O}_{\mathbf{3}}$ & $\mathbf{C a O}$ & $\mathbf{M g O}$ & $\mathbf{N a}_{\mathbf{2}} \mathbf{O}$ & $\mathbf{K}_{\mathbf{2}} \mathbf{O}$ & $\mathbf{S O}_{\mathbf{3}}$ & $\mathbf{C l -}$ & $\mathbf{R O X}$ & LOI & Specific Gravity \\
\hline OPC & 22.82 & 5.07 & 3.63 & 61.35 & 1.62 & 0.21 & 0.65 & 2.78 & 0.06 & 0.07 & 0.87 & 3.14 \\
\hline WSA & 76.38 & 9.42 & 2.88 & 4.95 & 5.05 & 3.42 & 6.56 & 0.65 & 1.57 & 3.71 & 1.54 & 2.27 \\
\hline
\end{tabular}

Table 2: Mineralogical composition of the OPC sample, mass \%.

\begin{tabular}{|c|c|c|c|c|}
\hline Phase Material & $\mathbf{C}_{3} \mathbf{S}$ & $\boldsymbol{\beta}_{\mathbf{C}} \mathbf{S}$ & $\mathbf{C}_{3} \mathbf{A}$ & $\mathbf{C}_{4} \mathbf{A F}$ \\
\hline OPC & 43.01 & 30 & 5.65 & 9.58 \\
\hline
\end{tabular}

Table 3: The batch composition of cement mixes, mass \%.

\begin{tabular}{|c|c|c|c|c|c|c|c|}
\hline Batch Material & $\mathbf{W}_{\mathbf{0}}$ & $\mathbf{W}_{\mathbf{1}}$ & $\mathbf{W}_{\mathbf{2}}$ & $\mathbf{W}_{\mathbf{3}}$ & $\mathbf{W}_{\mathbf{4}}$ & $\mathbf{W}_{\mathbf{5}}$ & $\mathbf{F i n e n e s s ,}_{\mathbf{c}} \mathbf{2} \mathbf{g}$ \\
\hline OPC & $! 00$ & 96 & 92 & 88 & 84 & 80 & 3400 \\
\hline WSA & --- & 5 & 10 & 15 & 20 & 30 & 6500 \\
\hline Fineness, $\mathrm{cm}^{2} / \mathrm{g}$ & 3400 & 3850 & 4100 & 4450 & 4780 & 5050 & \\
\hline
\end{tabular}




\section{Preparation and methods}

There are 6 cement batches from OPC and WSA as 100:0, 95:5, 90:10, 85:15, 80:20 and 75:25 having the symbols: W0, W1, W2, W3, W4 and W5, respectively. The blending process of the various cement batches (W0-W5) was done in a porcelain ball mill using five balls for two hours to assure the complete homogeneity of all cement batches. During mixing and casting, a definite percentage of polypropylene polymer (PPP) was added to the cement batch.

The standard water of consistency (WC) and setting times (initial and final) of the various cement pastes were directly determined using Vicat Apparatus [33-35] from the following relation:

$$
\text { WC, } \%=\mathrm{A} / \mathrm{C} \times 100 \text { Equation (1) }
$$

Where, A is the amount of water taken to produce a suitable paste, $C$ is the amount of cement mix (300g). The cement pastes were then cast using the predetermined water of consistency, moulded into one-inch cubic stainless steel moulds $(2.5 \times 2.5 \times$ $2.5 \mathrm{~cm}^{3}$ ) using about $500 \mathrm{~g}$ cement, vibrated manually for three minutes and then on a mechanical vibrator for another three minutes. The surface of the moulds was smoothed using a suitable spatula. Thereafter, the moulds were kept in a humidity chamber for 24 hours under $95 \pm 1$ relative humidity and room temperature $\left(20 \pm 1{ }^{\circ} \mathrm{C}\right)$, demoulded in the following day and soon immersed in water till the time of testing at 1, 3, 7, 28 and 90 days. The bulk density (BD) and total porosity $(\delta)$ of the hydrated cement pastes $[8,30,36]$ were calculated from the following equations:

$$
\begin{aligned}
& \text { B. } \mathrm{D},\left(\mathrm{g} / \mathrm{cm}^{3}\right)=\mathrm{W} 1 /(\mathrm{W} 1-\mathrm{W} 2) \times 1 \text { Equation }(2) \\
& \delta, \%=(\mathrm{W} 1-\mathrm{W} 3) /(\mathrm{W} 1-\mathrm{W} 2) \times 100 \text { Equation }(3)
\end{aligned}
$$

Where, W1, W2 and W3 are the saturated, suspended and dry weights, respectively. The compressive strength (CS) of the various hardened cement pastes [37] was measured as follows:

$$
\begin{gathered}
\mathrm{CS}=\mathrm{L}(\mathrm{KN}) / \mathrm{Sa}\left(\mathrm{cm}^{2}\right) \mathrm{KN} / \mathrm{m}^{2} \times 102\left(\mathrm{Kg} / \mathrm{cm}^{2}\right) / 10.2(\mathrm{MPa}) \\
\text { Equation (4) }
\end{gathered}
$$

Where $\mathrm{L}$ is the load taken, Sa is the surface area. Thereafter, about 10 grams of the broken specimens were first well ground, dried at $105{ }^{\circ} \mathrm{C}$ for an hour, and then were placed in a solution mixture of 1:1 methanol: acetone to stop the hydration [12,30-32]. About 10 grams of the broken specimens from the determination of compressive strength were first well ground, dried at $105{ }^{\circ} \mathrm{C}$ for $30 \mathrm{~min}$ and then were placed in a solution mixture of $1: 1$ methanol: acetone to stop the hydration $[8,38]$. The kinetics of hydration in terms of chemically bound water and free lime contents were also measured. About one gram of the sample was first dried at $105{ }^{\circ} \mathrm{C}$ for $24 \mathrm{~h}$, and then the chemically-bound water content (BWn) at each hydration age was determined on the basis of ignition loss at $1000{ }^{\circ} \mathrm{C}$ for $30 \mathrm{~min}$. soaking $[25,38,39]$ as follows:

$$
\text { BWn, \% = W1-W2/W2 × } 100 \text { Equation (5) }
$$

Where, BWn, W1 and W2 are bound water content, weight of sample before and after ignition, respectively. The free lime content (FLn) of the hydrated samples pre-dried at $105{ }^{\circ} \mathrm{C}$ for $24 \mathrm{~h}$ was also determined. About $0.5 \mathrm{~g}$ sample $+40 \mathrm{ml}$ ethylene glycol $\rightarrow$ heating to about 20 minutes without boiling. About 1-2 drops of $\mathrm{pH}$ indicator were added to the filtrate and then titrated against freshly prepared $0.1 \mathrm{~N} \mathrm{HCl}$ until the pink colour disappeared. The $0.1 \mathrm{~N}$ $\mathrm{HCl}$ was prepared using the following equation: Where, Wn, W1 and W2 are combined water content, weight of sample before and after ignition, respectively. The free lime content of the hydrated samples pre-dried at $105{ }^{\circ} \mathrm{C}$ for $24 \mathrm{~h}$ was also determined. About $0.5 \mathrm{~g}$ sample $+40 \mathrm{ml}$ ethylene glycol $\rightarrow$ heating to about 20 minutes without boiling. About 1-2 drops of $\mathrm{pH}$ indicator were added to the filtrate and then titrated against freshly prepared $0.1 \mathrm{~N} \mathrm{HCl}$ until the pink colour disappeared. The $0.1 \mathrm{~N} \mathrm{HCl}$ was prepared using the following equation:

$$
\mathrm{V} 1=\mathrm{N} \times \mathrm{V} 2 \times \mathrm{W}(7) \times 100 / \mathrm{D} \times \mathrm{P} \times 1000 \text { Equation (6) }
$$

Where, V1 is the volume of $\mathrm{HCl}$ concentration, V2 is the volume required, $\mathrm{N}$ is the normality required, $\mathrm{W}$ is the equivalent weight, $\mathrm{D}$ is the density of $\mathrm{HCl}$ concentration and $\mathrm{P}$ is the purity (\%). The heating and titration were repeated several times until the pink colour did not appear on heating. The free lime content $[14,30,32,36]$ was calculated from the following relation:

$$
\text { FLn, } \%=(V \times 0.0033 / 1) \times 100 \text { Equation }(7)
$$

Where, FLn and V are the free lime content and the volume of $0.1 \mathrm{~N} \mathrm{HCl}$ taken on titration, respectively.

\section{Results and Discussion}

\section{Water of consistency and setting time}

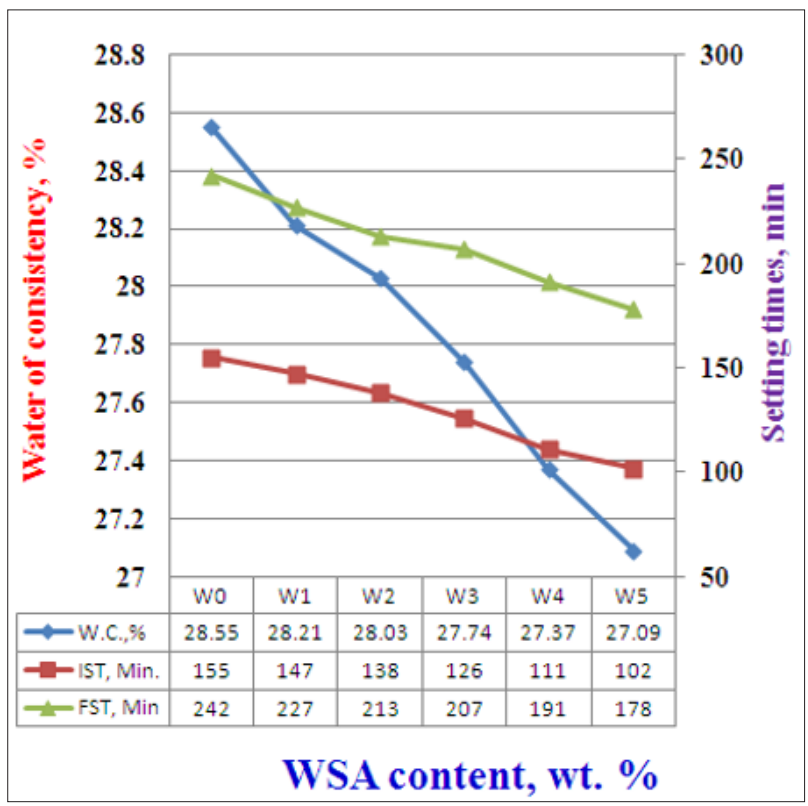

Figure 3: Water of consistency and setting time of cement blends containing WSA cured up to 90 days.

Figure 3 indicates the water of consistency and setting times (Initial and final) of all cement mixes (W0-W5). Water of consistency 
of the pure OPC pastes (P0) was $28.65 \%$. This ratio was seemed to gradually decrease with the increase of WSA content (W1-W5), i.e. the higher WSA content is the lower water absorption. This is mainly due to the presence of water reducing admixture $[24,28,40]$. On the other side, the initial and final setting times also diminished and decreased with WSA content. This is principally contributed to the spongy nature of WSA particles which tends to absorb more water during mixing process, but the admixture reduced the ability of the WSA absorbability $[10,12,30,31,39]$. Therefore, it can be concluded that the WSA acts as an accelerator. Also, the diminishing of the cement portion due to the incorporation of WSA is another reason for the set acceleration.

\section{Chemically bound water contents}

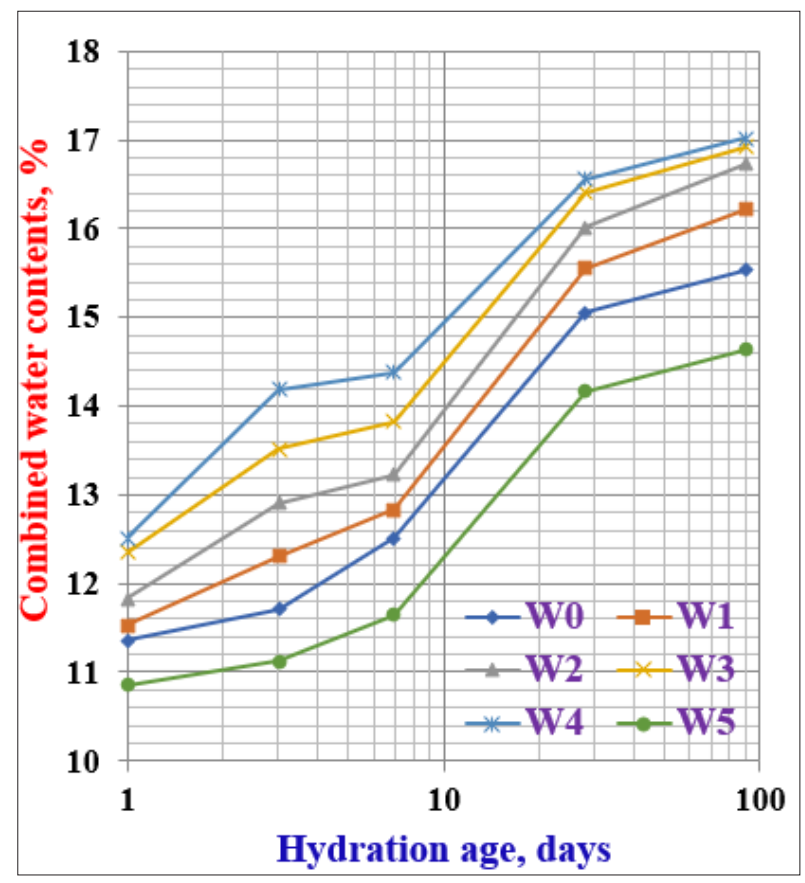

Figure 4: Chemically bound water contents of cement pastes containing WSA hydrated up to 90 days.

The chemically bound water contents of the various cement pastes containing WSA are shown in Figure 4. Generally, the bound water contents increased as the hydration time proceeded up to 90 days. This is principally due to the hydration of the main cement phases, especially $\mathrm{C}_{3} \mathrm{~S}, \mathrm{C}_{3} \mathrm{~A}$ and $\mathrm{C}_{4} \mathrm{AF}$ at early ages of hydration up to 28 days, whereas $\beta-C_{2} S$ often hydrates at later ages from 28 days onward $[18,30,31]$. The bound water contents slightly increased as the WSA content increased up to $20 \%$, and then suddenly decreased sharply with further increase of WSA almost at all curing ages, i.e. the cement blends W1, W2, W3 and W4 are slightly higher than those of the pure OPC (W0). This is primarily due to the pozzolanic reactions of WSA through which the constituents of WSA could be reacted with the $\mathrm{Ca}(\mathrm{OH})_{2}$ resulting from the hydration of $\mathrm{C}_{3} \mathrm{~S}$ at early stages of hydration and $\beta-C_{2} S$ at later stages to finally produce addition CSH. The bound water contents of W5 became lower than with the control mix (W0). The lower values of bound water may be due to the unburned carbon existed in WSA, and to the dilution action of WSA $[10,12,30,31,41,42]$. Accordingly, it can be concluded that the optimum addition of WSA does not exceed $20 \mathrm{wt}$. \% because the higher amounts of WSA is undesirable due to its adverse effect, i.e. the higher quantity of WSA must be avoided because it may be hindered the hydration of cement phases in addition the high deficiency of the main binding material of the cement itself.

\section{Free lime contents}

Figure 5 illustrates the free lime contents of the various cement pastes incorporating WSA hydrated up to 90 days. It is clear that the free lime contents of the OPC (W0) gradually increased with the increase of hydration ages as an indication of the enhancement in the rate of hydration $[24,28,30,31]$. As the WSA content increased in the cement, the free lime content was slightly decreased at all hydration ages up to 90 days to become lower than those of the control (W0). The increase of free lime content as in W0 is due to the normal hydration process of the silicate phases of the cement $\left(\mathrm{C}_{3} \mathrm{~S}\right.$ and $\left.\beta-\mathrm{C}_{2} \mathrm{~S}\right)$, while the decrease is due to the pozzolanic reaction mechanism between the active silica of the WSA constituents and the resulting $\mathrm{Ca}(\mathrm{OH})_{2}$ that is often coming from the hydration of $\mathrm{C}_{3} \mathrm{~S}$ at early ages and $\beta-C_{2} S$ at later ages of hydration as follows:

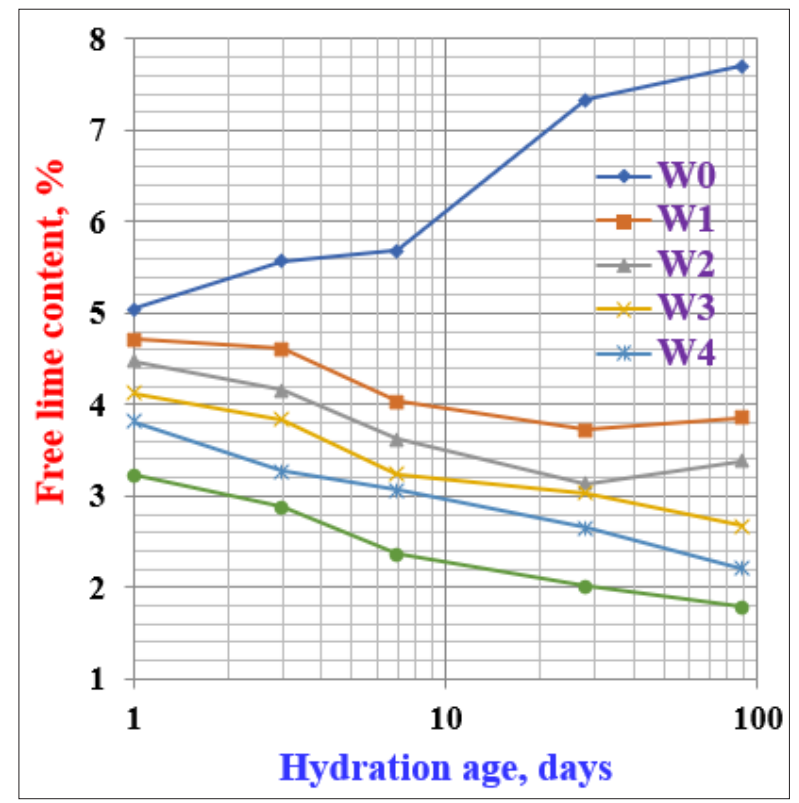

Figure 5: Free lime contents of cement blends containing WSA hydrated up to 90 days.

$$
\begin{aligned}
& 3 \mathrm{C}_{3} \mathrm{~S}+6 \mathrm{H}_{2} \mathrm{O} \rightarrow \mathrm{C}_{3} \mathrm{~S}_{2} \mathrm{H}_{3}+3 \mathrm{Ca}(\mathrm{OH})_{2} \text { Equation (8) } \\
& 2 \beta-\mathrm{C}_{2} \mathrm{~S}+4 \mathrm{H}_{2} \mathrm{O} \rightarrow \mathrm{C}_{3} \mathrm{~S}_{2} \mathrm{H}_{3}+\mathrm{Ca}(\mathrm{OH})_{2} \text { Equation (9) }
\end{aligned}
$$

The obtained results proved that the WSA acts as a pozzolanic material, and therefore the higher the amount of PA, the higher is the pozzolanic activity $[11,14,15,41,42]$. 


\section{Bulk density and total porosity}

Figure $6 \& 7$ demonstrate the graphs of the bulk density and total porosity of the various cement pastes versus the hydration ages up to 90 days. Generally, the bulk density of the various hardened cement pastes increased as the hydration period progressed up to 90 days, while the total porosity decreased. This is mainly contributed to the fact that: as the hydration ages proceed, the hydration process starts to produce CSH which soon deposits in the pore structure leading to a decrease in the total porosity. This reflected positively on the bulk density, i.e. the bulk density increased while the total porosity decreased $[30,31,43]$. The bulk density of the cement mixes containing WSA (W1-W4) gradually increased as the WSA content increased up to 20wt. \% (W4), whereas the total porosity decreased, i.e. the cement blends W1, W2, W3 and W4 are slightly higher than those of the of the pure OPC (W0). This is evidently due to the formation of additional CSH from the pozzolanic reactions of the active nano silica of WSA with the constituents of cement through which the constituents of WSA could be reacted with the $\mathrm{Ca}(\mathrm{OH})_{2}$ that is released from the hydration of $\mathrm{C}_{3} \mathrm{~S}$ at early stages of hydration and $\beta-\mathrm{C}_{2} \mathrm{~S}$ at later stages to produce addition $\mathrm{CSH}[26,30$ 32]. The addition of more than 20wt. \% WSA, the bulk density was suddenly decreased, while the total porosity increased at all hydration ages. This is principally due to the decrease in the main binding material of the OPC (W0), and also the higher quantity of WSA may obstruct and hinder the hydration process, i.e. it affected negatively and decreased the rate of hydration accompanied by a decrease of bulk density $[10,18,30,32,36,42]$. Hence, the increase of total porosity and the decrease of bulk density resulted with the incorporation of large amounts of WSA affected the amount of the used OPC. As a result, it was not sufficient for inducing the reaction with silica from WSA.

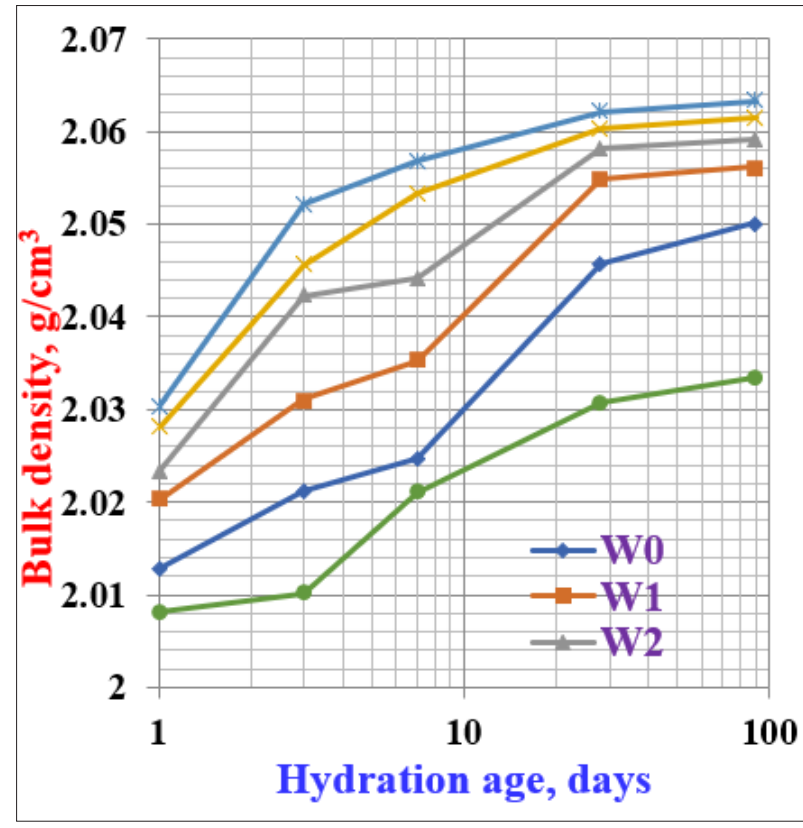

Figure 6: Bulk density of cement blends containing WSA cured up to 90 days.

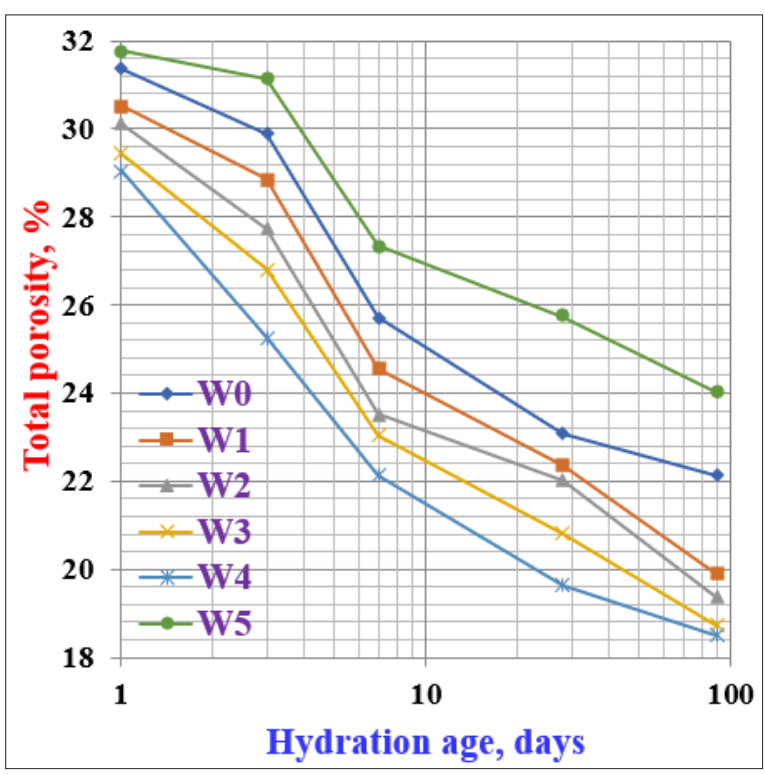

Figure 7: Total porosity of cement blends containing WSA cured up to 90 days.

\section{Compressive strength}

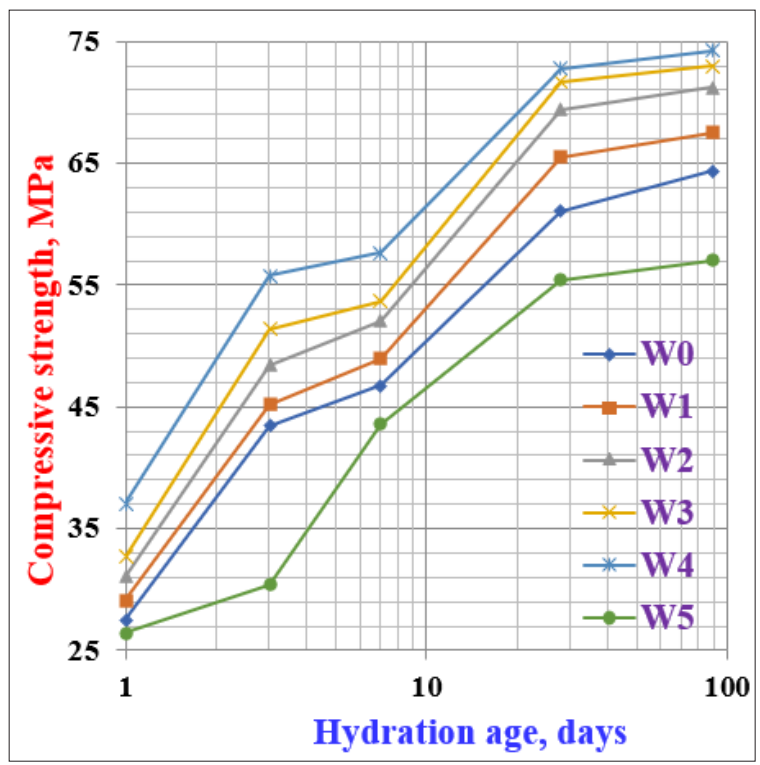

Figure 8: Compressive strength of the different cement pastes containing WSA cured up to 90 days.

The $\mathrm{w} / \mathrm{c}$ ratio influences the workability and durability of cement pastes and concrete, which in turn influences its strength, i.e. the decrease of $\mathrm{w} / \mathrm{c}$-ratio results in an increase of workability accompanied by an increase in the strength, and the opposite is correct. Figure 8 represents the compressive strength of the various cement pastes (W0-W5) as a function of hydration ages up to 90 days. Generally, the compressive strength improved and gradually enhanced as the hydration time proceeded up to 90 days. This is mainly attributed to the formation of hydration products (CSH). These CSHs are always deposited into the pore system of the hardened cement pastes. As a result, a decrease in the total porosity was obtained. This evidently accompanied by an increase 
in the bulk density. This may be due to the good dispersion by the used admixture and good compaction of the hardened samples during casting. Consequently, this would be reflected positively on the compressive strength. As a result, the compressive strength improved and increased $[8,14,36,43,44]$. The compressive strength also enhanced as the WSA content increased at all curing ages of hydration. This is essentially due to the formation of additional $\mathrm{CSH}$ that is coming from the pozzolanic reactions of the active nano silica and nano alumina from WSA with the free lime released from the hydration of $\mathrm{C}_{3} \mathrm{~S}$ and $\beta-\mathrm{C}_{2} \mathrm{~S}$ of cement to produce cubic crystals of hydrogarnet $\left(\mathrm{C}_{3}\right.$ A. $\left.\mathrm{S}_{2} . \mathrm{H}_{\mathrm{n}}\right)$ as follows:

$$
\mathrm{Al}_{2} \mathrm{O}_{3}+\mathrm{SiO}_{2}+\mathrm{Ca}(\mathrm{OH})_{2} \rightarrow \mathrm{C}_{3} \mathrm{~A} \cdot \mathrm{S}_{2} \cdot \mathrm{H}_{\mathrm{n}} \text { Equation (10) }
$$

The decrease of free lime improved the physicochemical and mechanical properties of the hardened cement pastes, and therefore the compressive strength further improved and enhanced [14,22,32,44-46]. Moreover, the decrease of $\mathrm{w} / \mathrm{c}$ ratio due to the presence of the polymer admixture (Figure 1) improved in the physical and mechanical strength of the hardened cement samples. The compressive strength also increased as the WSA content increased only up to $20 \mathrm{wt}$. \%, and then suddenly decreased. The increase of compressive strength is related to the pozzolanic reactivity of WSA. This would be led to the segmentation of large capillary pores and nucleation sites due to the continuous deposition of hydration products (CSHs) from the normal hydration of cement phases and the additional CSHs from the pozzolanic reactions of WSA with the evolved free lime [43-46] The decrease is due to the fact that the replacing of WSA at the expense of the essential cementitious material of cement, and on the other side the higher amount of WSA standard up as an obstacle against the normal hydration of cement phases. So, the rate of hydration decreased. Accordingly, this should be reflected negatively on the compressive strength $[22,47,48]$. The cement mix of W4 exhibited the higher values of compressive strength, whilist that of W5 recorded the lowest. On this basis, the cement batch containing $20 \%$ WSA (W4) is the optimum mix. Hence, the WSA does not only improve and enhance the various characteristics of the cement, but from an economical point of view, it also reduces the cost of the very expensive cement production.

\section{Conclusion}

The following overall conclusions could be obtained:

a) The heat of hydration gradually increased with the addition of PA at the expense of the cement.

b) Water of consistency and setting times are decreased, and therefore WSA acts as an accelerator. The decrease of water of consistency is due to the presence of the water reducing admixture.

c) The chemically bound water contents increased as the hydration ages were proceeded, and also with the increase of WSA only up to $20 \mathrm{wt}$. \%, but then, decreased with further increase of WSA. d) The free lime content increased up to 90 days with W0 containing no WSA, whilst it decreased with cement blends containing WSA.

e) The bulk density improved and enhanced as the WSA content increased up to $20 \mathrm{wt}$. \%, and then decreased with further increase of WSA, whilst the total porosity decreased with replacing WSA up to $20 \mathrm{wt}$. \%, and then increased onward.

f) The compressive strength significantly improved with increasing the WSA content only up to $20 \mathrm{wt}$. \%, and then declined suddenly at all curing ages of hydration. The increase could be done by increasing the pozzolanic reactions that are leading to reduce of $\mathrm{Ca}(\mathrm{OH})_{2}$ content which is coming from the hydration of $C_{3} S$ and $\beta-C_{2} S$ phases of the cement, and by enhancing the precipitation sites of hydration products into the pore system of the hardened cement pastes. The decrease is due to the deficiency of the main binding material of the cement.

g) The addition of $20 \%$ WSA to the cement could be applied without any adverse effects on its physical, chemical and mechanical properties, but on contrast, they improved and enhanced.

h) The polyprobyene admixture (PPP) is the mean reason responsible for the modification and improving most of the physical, chemical, and mechanical properties of the hardened cement pastes.

i) The WSA could improve the compaction and composition of the hardened cement pastes to a large extent because it possesses certain pozzolanic reactions that can further enhance its physical and mechanical properties especially compressive strength, i.e. these pozzolanic reactions of WSA played a vital role to form additional gel-phases that support and enhance all the specific properties of the cement.

\section{Acknowledgement}

Authors wish to express their deep thanks to NRC for helping to obtain materials, processing, preparing, molding and measuring all of the obtained data of the study.

\section{References}

1. Zhang H, Hu J, Qi Y, Li C, Chen J, et al. (2017) Emission characterization, environmental impact, and control measure of PM2.5 emitted from agricultural crop residue burning in China. Journal of Cleaner Production 149: 629-635.

2. Eisentraut ABA (2012) Technology road map bioenergy for heat and power. International Agency of Energy, France.

3. Aksogan O, Binici H, Ortlek E (2016) Durability of concrete made by partial replacement of fine aggregate by colemanite and barite and cement by ashes of corn stalk, wheat straw and sunflower stalk ashes. Construction and Building Materials 106: 253-263.

4. Binici H, Ortlek E (2015) Engineering properties of concrete made with cholemanite, barite, corn stalk, wheat straw and sunflower stalk ash. European Journal of Engineering and Technology 3(4): 23-34.

5. Wang S, Miller A, Llamazos E, Fonseca F, Baxter L (2008) Biomass fly ash in concrete: Mixture proportioning and mechanical properties. Fuel 87(3): 365-371. 
6. Antiohos S, Maganari K, Tsimas S (2005) Evaluation of blends of high and low calcium fly ashes for use as supplementary cementing materials. Cement and Concrete Composites 27(3): 349-356.

7. Balendran RV, Martin Buades WH (2000) The influence of high temperature curing on the compressive, tensile and flexural strength of pulverized fuel ash concrete. Building and Environment 35(5): 415-423.

8. Darweesh HHM (2005) Effect of the combination of some pozzolanic wastes on the properties of Portland cement pastes IIC. The Italian cement industry, Italy, 808: 298-311.

9. El Didamony H, Darweesh HH, Mostafa RA (2008) Characteristics of pozzolanic cement pastes Part I: Physico-mechanical properties. Sil Ind (Cer Sci \& Techn) Belgium, 73(11-12): 193-200.

10. Darweesh HHM, Abo El Suoud MR (2015) Quaternary cement composites from industrial byproducts to avoid the environmental pollution. J EC Chemistry 2(1): 78-91.

11. Darweesh HHM (2017) Geopolymer cements from slag, fly ash and silica fume activated with sodium hydroxide and water glass. Interceram International 6(1): 226-231.

12. Darweesh HHM (2017) Mortar composites based on industrial wastes. International Journal of Materials and Lifetime 3(1): 1-8.

13. Waswa Sabuni B, Syagga PM, Dulo SO, Kamau GN (2003) Rice husk ash cement-An Alternative pozzolana cement for Kenyan building industry. Journal of Civil Engineering JKUAT 8: 13-26.

14. Darweesh HHM, Abo El Suoud MR (2014) Setting, hardening and mechanical properties of some cement/agrowaste composites-Part I. Amer J Mining and Metallurgy 2(2): 32-40.

15. Darweesh HHM, Abo El Suoud MR (2019) Influence of sugarcane bagasse ash on Portland cement characteristics. Indian J of Engineering 16: $252-266$

16. Abdel Kader AH, Darweesh HHM (2010) Setting and hardening of agro/ cement composites. Bio Resources 5(1): 43-54.

17. Darweesh HHM, Abo El Suoud MR (2019) Palm ash as a pozzolanic material for Portland cement pastes. To Chemistry Journal 4(2): 72-87.

18. Darweesh HHM, Abo El Suoud MR (2017) Saw dust ash substitution for cement pastes-Part I. American J of Construction and Building Materials 3(5): 63-71.

19. Raheem AA, Olasunkanmi BS, Folorunso CS (2012) Saw dust ash as partial replacement for cement in concrete. Intern Journ of Organization Technology and Management in Construction 4(2): 474-479.

20. Shih JY, Chang TP, Hsiao TC (2006) Effect of nanosilica on characterization of Portland cement composite. Materials Science and Engineering: A 424(1-2): 266-274

21. Ganesan K, Rajagopal K, Thangavel K (2007) Evaluation of bagasse ash as supplementary cementitious material. Cem Concr Comp 29: 515-524.

22. Darweesh HHM (2012) Setting, hardening and strength properties of cement pastes with zeolite alone or in combination with slag. Interceram Intern (Intern Cer Review), Germany, 1: 52-57.

23. Cordeiro GC, Toledo Filho RD, Tavares LM, Fairbairn EMR (2008) Pozzolanic activity and filler effect of sugarcane bagasse ash in Portland cement and lime mortars. Cem Concr Comp 30(5): 410-418.

24. Darweesh HHM, Abo El Suoud MR (2019) Influence of sugarcane bagasse ash on Portland cement characteristics. Indian J of Engineering 16: 252-266.

25. Chusilp N, Jaturapitakkul C, Kiattikomol K (2009) Utilization of bagasse ash as a pozzolanic material in concrete. Constr Build Mater 23(11): 3352-3358.
26. Akram T, Memon SA, Obaid H (2009) Production of low cost selfcompacting concrete using bagasse ash. Constr Build Mater 23(2): 703712 .

27. Felekoğlu B, Türkel S, Baradan B (2007) Effect of water/cement ratio on the fresh and hardened properties of self-compacting concrete, Building and Environment 42(4): 1795-1802.

28. Darweesh HHM, Abo El Suoud MR (2017) Saw dust ash substitution for cement pastes-Part I. American J of Construction and Building Materials 3(5): 63-71.

29. Mangi SA, Jamaluddin N, Wan Ibrahim MH, Noridah M, Sohu S (2017) Utilization of sawdust ash as cement replacement for the concrete production: A review. Engineering Science and Technology International Research Journal 1(3): 11-15.

30. Hewlett PC (2004) Lea's chemistry of cement and concrete. ( $5^{\text {th }}$ edn), Elsevier Science \& Technology Books, Oxford, England.

31. Neville AM (2011) Properties of Concrete. ( $5^{\text {th }}$ edn), Longman Essex, UK.

32. Echart A, Ludwig HM, Stark J (1995) Hydration of the four main Portland cement clinker phases. Zement Kalk Gips 48(8): 443-452.

33. ASTM-Standards C187-86 (1993) Standard test method for normal water of consistency of hydraulic cement. pp. 148-150.

34. ASTM-Standards C191-92 (1993) Standard test method for setting time of hydraulic cement. pp. 866-868.

35. ASTM-Standards C191-13 (2013) Standard test method for time of setting of hydraulic cement by vicat needle. ASTM International West Conshohocken, USA.

36. Darweesh HHM (2014) Utilization of perlite rock in blended cement-part I: Physicomechanical properties. Direct Research Journal of Chemistry and Material Sciences, pp: 2354-4163.

37. (1993) Standard test method for compressive strength of dimension stone. ASTM-Standards C170-90, pp. 828-830.

38. kondo R, Abo-El-Enein SA, Daimon M (1975) kinetics and mechanisms of hydrothermal reaction of granulated blast furnace slag. Bulletin of the chemical Society Japan 48(1): 222-226.

39. Karim MR, Zain MFM, Jamil M (2012) Strength of mortar and concrete as influenced by rice husk ash: A review. World Applied Sciences Journal 19(10): 1501-1513.

40. Darweesh HHM, Abo El Anwar A, Mekky HS (2018) Addition of limestone at the expense of gypsum in Portland cement. Interceram International Ceramic Review 67(5): 18-27.

41. Ayoub MMH, Darweesh HHM, Negim SM (2008) Utilization of hydrophilic copolymers as super-plastisizers for cement pastes. Cem Hormigon 910: 4-15.

42. Darweesh HHM (2014) Utilization of Ca-lignosulphonate prepared from black liquor waste as a cement superplasticizer. J Chemistry and Materials Research 1(2): 28-34

43. Ibrahim NS, Heikal M, Ismail MN (2015) Physico-mechanical, microstructure characteristics and fire resistance of cement pastes containing $\mathrm{Al}_{2} \mathrm{O}_{3}$ nano-particles. Const Build Mater 91: 232-242.

44. Givi AN, Rashid SA, Aziz FNA, Salleh MAM (2010) Experimental investigation of the size effects of $\mathrm{SiO}_{2}$ nano-particles on the mechanical properties of binary blended concrete. Composites Part B: Engineering 41(8): 673-677.

45. Nazari A, Riahi S (2011) The effects of $\mathrm{SiO}_{2}$ nanoparticles on physical and mechanical properties of high strength compacting concrete. Compos Part B-Eng 42(3): 570-578. 
46. Aleem SAE, Heikal M, Morsi WM (2015) Hydration characteristic, thermal expansion and microstructure of cement containing nano-silica. Const Buil Mater 59: 151-160.

47. Ye Q, Zhang ZN, Kong DY, Chen RS (2007) Influence of nano-SiO ${ }_{2}$ addition on properties of hardened cement paste as compared with silica fume. Constr Build Mater 21(3): 539-545.
48. Rukzon S, Chindaprasirt P (2006) Strength of ternary blended cement mortar containing Portland cement, rice husk ash and fly ash. J Eng Inst 17: 33-37.

For possible submissions Click below: 